\title{
An empirical study on website usability elements and how they affect search engine optimisation
}

\author{
Authors: \\ Eugene B. Visser ${ }^{1}$ \\ Melius Weideman ${ }^{1}$ \\ Affiliations: \\ ${ }^{1}$ Faculty of Informatics and \\ Design, Cape Peninsula \\ University of Technology, \\ South Africa \\ Correspondence to: \\ Melius Weideman \\ Email: \\ weidemanm@cput.ac.za \\ Postal address: \\ PO Box 652, Cape Town \\ 8000 , South Africa \\ Dates: \\ Received: 07 May 2010 \\ Accepted: 17 Nov. 2010 \\ Published: 25 Mar. 2011 \\ How to cite this article: \\ Visser, E.B. \& Weideman, \\ M., 2011, 'An empirical \\ study on website usability \\ elements and how they \\ affect search engine \\ optimisation', SA Journal of \\ Information Management \\ 13(1), Art. \#428, 9 pages. \\ doi: $10.4102 / \mathrm{sajim}$. \\ v13i1.428
}

The primary objective of this research project was to identify and investigate the website usability attributes which are in contradiction with search engine optimisation elements. The secondary objective was to determine if these usability attributes affect conversion. Although the literature review identifies the contradictions, experts disagree about their existence.

An experiment was conducted, whereby the conversion and/or traffic ratio results of an existing control website were compared to a usability-designed version of the control website, namely the experimental website. All optimisation elements were ignored, thus implementing only usability.

The results clearly show that inclusion of the usability attributes positively affect conversion, indicating that usability is a prerequisite for effective website design. Search engine optimisation is also a prerequisite for the very reason that if a website does not rank on the first page of the search engine result page for a given keyword, then that website might as well not exist.

According to this empirical work, usability is in contradiction to search engine optimisation best practices. Therefore the two need to be weighed up in terms of importance towards search engines and visitors.

\section{Introduction}

Search Engine Optimisation (SEO) is the process of designing or making alterations to a website in such a way that the search engines can find and index the given website with greater ease, resulting in improved rankings (Weideman 2009:14). Website usability (WU) refers to the 'feeling' of how easy a website is to use, as experienced by a human user (Nielsen \& Loranger 2006:xvi). Both of these website attributes are important for different reasons and both require a concerted effort to implement on a website. SEO is needed to please one specific audience, namely search engine crawlers, whilst WU is aimed at the human user audience. These two audiences are highly dependent on each other, but sometimes operate in a way where one disregards the other.

Johnson (2008) associates the development of civilised societies with WU and usefulness. The same author stated that neither the development of civilised societies nor WU is considered to be consistent. With the launch of the first graphical web browser (i.e. Mosaic) in 1993, enthusiasts with no experience in usability and/or design started creating a variety of websites. Almost two decades later, websites are often still not developed with WU or usefulness in mind as a primary objective (Johnson 2008; Nielsen 2007).

According to James (2002) WU is of major importance to attract and retain visitors. Nielsen (2003) agrees with this author, stating that website usability is crucial for survival. One reason for this phenomenon is stated as being that if a visitor's needs are not satisfied on a particular website the visitor will simply leave and visit a website that will do so (Kritzinger \& Weideman 2008).

Because WU is of crucial importance, it was deemed necessary to define usability from various perspectives. Bruno and Al-Qaimari (2004:1-2) accumulated multiple definitions for usability compiled by different authors, indicating how those definitions evolved over time.

Shackel (1981): '[a system's] capability in human functional terms to be used easily and effectively by the specific range of users, given specified training and support, to fulfil a specific range of tasks, within a specific range of environmental scenarios'.

Neilson and Shneiderman (1993): 'ease of learning (learnability), speed of performance (efficiency), low error rate, retention over time (memorability), and user attitude (subject satisfaction)'. 
Preece (1994): 'a measure of the ease with which a system can be learned or used, its safety, effectiveness and efficiency, and the attitude of its users towards it'.

Preece (1997) International Standard Organisation (ISO/ DIS 9241-11.2): 'the extent to which a product can be used by specified users to achieve specific goals with effectiveness and satisfaction in a specified context of use'.

Krug (2000): 'making sure that something works well: that a person of average (or even below average) ability and experience can use the thing - whether it's a website, a fighter jet, or a revolving door - for its intended purpose without getting hopelessly frustrated'.

Although these practical examples differ in some ways, they all appear to agree that 'targeted users', 'complexity of tasks', 'type of technology' and 'the environment' affect usability and interaction in some way. However, it is not surprising to see that Krug (2000) as well as Nielsen and Loranger (2006) were the only ones that referred to a website within their definitions of usability. This is a result of the fact that these definitions were created after the 1990s, during which period the Internet was born.

Eisenberg, Quarto-vonTivadar, Davis and Crosby defined WU more recently as follows:

\begin{abstract}
Usability addresses the ways a site effectively implements the body of knowledge concerning a visitor's ability to interact successfully in an online environment. The goal of usability is to remove any obstacles impeding the experience and process of online interaction.
\end{abstract}

(Eisenberg, Quarto-vonTivadar, Davis and Crosby 2008:158)

This definition identifies the mechanical usability problems and not persuasive usability problems. It is evident that the definitions constructed prior to 2000 were predominantly based on software engineering (human interface design). Although the definitions after 2000 considered websites within the usability definition, there are clear differences between website usability and software usability (human interface design). In an attempt to clearly show this difference, the two concepts are defined in the following section.

\section{Website usability}

Consider for a moment that a user intends to purchase a product and/or service on the Internet. The user is browsing the Internet in search of the appropriate product at the right price and eventually lands on a website where the product and price is satisfactory. If the user encounters an error during the checkout procedure (or during browsing), no obligation exists that will force the user to return to the same website to attempt the buying (browsing) process again. In fact, it makes better sense to search for a competitor website as it is simply easier to do so than to find out how to fix the error, if possible at all.

\section{Software usability (human interface design)}

Once a software product has been purchased for use within an office or home environment, the product must sustain its usefulness, over and above its actual purpose, by means of usability. Usability in this instance refers more to error handling and the understanding of how the software operates. If a critical error occurs during the use of a software package, a user must be able to recover from the error with minimal effort and not be hampered in the process due to loss of data. This is important because it is impractical for the user to buy another product in the hope that a similar error will not occur again.

\section{Previous work}

No SEO or WU contradictions other than identified by Nielsen and Loranger (2006:166) (keywords) have been identified during the review. Ironically, when considering WU experts' opinions regarding SEO best practice in terms of concept and application, the contradictions start to surface. The website usability attributes listed in this section have been identified by the current authors to be in contradiction to SEO, based on the website usability definition of Eisenberg et al. (2008:158).

\section{Trust and credibility as a website usability attribute}

Barnard and Wesson (2003:258-259) have identified the WU attribute trust as being a critical success factor. According to the same authors, Internet users have serious concerns regarding their privacy on the Internet. Ease-of-use, credibility of information on a website and security all form part of the WU trust attribute (Barnard \& Wesson 2003:259). Although many different ways exist to address trust, Nielsen and Tahir $(2001: 10-13,201)$ suggest emphasising the following information on a website as part of WU:

- privacy policy

- about us

- company overview webpage (company values, management team, etc.)

- feedback

- testimonials

- contact information.

Eisenberg et al. (2008:32, 192, 195, 196, 240) agrees with Nielsen and Tahir (2001) on the WU sub-attributes and add that the WU attributes of credibility and trust are interwoven. In addition, Nielsen (2005) states that an author photo (company owner) can offer a more personable impression, which in turn enhances credibility and thus also trust. In addition, the photo can also connect the virtual and physical world, making it easier for the visitor to relate to the owner.

\section{Single page view, content and frames as website usability attributes}

Bevan (2005) compared the draft International Organisation for Standardisation and/or Draft International Standard 
(ISO/DIS 9241-151:2005) design and usability guidelines (International Standard for user-centred design of web user interface) and the Health and Human Service (HHS) design and usability guidelines (US Department of Health and Human Service). The HHS guidelines suggest that the content, page lengths, number of words and sentences should be limited on a website in the interest of WU. The ISO guidelines concur with the HHS guidelines and adds that content on a webpage should fit on the expected size of a display area. In addition, the HHS guidelines suggest the use of frames in certain circumstances whereby the ISO 9241-151 guidelines indicate that frames should be used with care. The HHS guidelines also suggest placing important items to the top of all webpages, indicating that less emphasis should be applied to content when considering the WU attributes trust and credibility.

Johnson (2007:169) states that too much text is 'bad writing' and is something that frequently occurs on websites. The author suggests as a guideline that text on each page should be halved. The remaining text should then be halved again. Nielsen and Loranger (2006:30-35) interpreted content from a slightly different perspective and estimate that visitors often view a webpage for $45-60$ seconds. The same authors estimate that a visitor could read a maximum of 200 words during that time period. This indicates that the amount of text placed on a webpage is only important and considered from a visitor's perspective and not from a search engine's perspective. It is thus the message that is conveyed (webpage objective) in the 200 words of text that is read by the visitor during the time constraint of 60 seconds. In summary, the ideal length in terms of number of words should be found enough to allow search engines a rich harvest of keywords, but not too many to frighten off human readers.

\section{Keywords as a website usability attribute}

Weideman (2009:55) claims that keyword usage, including density, on webpages ranks two out of 17 factors in importance in SEO implementation. However, according to Nielsen and Loranger (2006:166), keyword density is the one SEO element that is in direct contradiction to WU. The same authors state that SEO consultants often overload content with the same targeted keywords reducing readability. It is thus suggested to use multi-word phrase targeting. Johnson (2007:153) conversely, states that using different terms for the same concept is one of the best ways to confuse users. According to Johnson (2007), users will spend all their time attempting to figure out how the terms relate as opposed to spending time achieving the user's objective. Thus, keyword density as well as keyword inclusion are factors to be avoided from a WU perspective. In research currently underway the authors attempt to investigate the crossover point between keyword rich body text and spamdexing (Zuze and Weideman 2010).

\section{Images as a website usability attribute}

According to Ngindana and Weideman (2004), visitors often prefer graphic-based webpages as opposed to text-based webpages. The same authors have found that Flash and/ or graphic images are aesthetically pleasing to visitors, especially when using graphics as part of a websites' navigation. It is thus clear that graphical aids allow for easy visitor navigation. George $(2005: 171,178)$ agrees and found that visitors first notice colours and images before browsing from left to right and top to bottom, indicating that visitors first and foremost focus their attention on images.

Nielsen and Loranger (2006:247) believe that large blocks of text in images (text images) should be used in moderation. The use of text images is not recommended for a number of reasons. However, snippets of text such as found in navigation buttons are appropriate.

Eisenberg et al. (2008:168-169) agrees with Ngindana and Weideman (2004) and explains that powerful images placed 'above the page fold' can draw a lot of attention and could thus be used to emphasise what a business wants the visitor to focus on.

In summary, WU attributes focus primarily on what makes the website visitor respond. WU experts tend to consider search engines where possible. However, search engines are not considered as a priority. This is confirmed by some website usability experts who state that search engines do not carry credit cards (Eisenberg et al. 2008:223). Although this statement is true, the irony is that search engines could potentially drive a large number of visitors (with credit cards) to a website.

\section{Search engine optimisation contradictions}

Conceptually the single most important SEO element (namely content) is negatively affected by:

- trust and credibility (i.e. privacy policy, about us, company overview, feedback, testimonials and contact form)

- single page view

- minimising content

- frames

- keywords

- images.

Search engines depend on content to fully understand the purpose of any given website. Trust and credibility are both built by the use of generic content which does not assist the search engine in identifying the purpose of the particular website. The lack of keywords along with minimising content will limit the search engines' ability to be more successful at an interpretation of the websites' purpose.

Murphy and Kielgast (2008:90) state that more than 85\% of all purchases that occur on the Internet started with a search. Further research demonstrates that there are three major search engines (i.e. Google, Yahoo! and MSN/Live/ Bing) that dominate the search engine market with Google being by far the biggest (Sullivan 2004; Sullivan 2006). Recent figures released indicated that Bing has taken over the second 
TABLE 1: Search engine market share (Sullivan 2004; Sullivan 2006; Searchenginewatch 2009)

\begin{tabular}{lccc}
\hline $\begin{array}{l}\text { Search engine } \\
\text { market share }\end{array}$ & $\begin{array}{c}\mathbf{2 0 0 4} \\
\text { Web Side Story } \\
\text { (Sullivan 2004) }^{+}\end{array}$ & $\begin{array}{c}\mathbf{2 0 0 6} \\
\text { Nielsen/NetRatings } \\
\text { (Sullivan 2006) }^{*}\end{array}$ & $\begin{array}{c}\mathbf{2 0 0 9} \\
\text { Nielsen } \\
\text { (Searchenginewatch 2009) }^{\text {s }}\end{array}$ \\
\hline Google & $40.90 \%$ & $49.20 \%$ & $64.60 \%$ \\
Yahoo! & $27.40 \%$ & $23.80 \%$ & $16.00 \%$ \\
$\begin{array}{l}\text { MSN/Live/ } \\
\text { Bing }\end{array}$ & $19.60 \%$ & $9.60 \%$ & $10.70 \%$ \\
$\begin{array}{l}\text { Other Search } \\
\text { Engines }\end{array}$ & $12.10 \%$ & $17.40 \%$ & $8.70 \%$ \\
\hline
\end{tabular}

, Sullivan, D, 2004, Google tops, but Yahoo switch success so far, viewed 04 May 2010 from http://searchenginewatch.com/3334881; ”, Sullivan, D., 2006, Nielsen NetRating Search Engine Ratings, viewed 01 May 2010, from http://searchenginewatch.com/2156451;

\&. Searchenginewatch, 2009, Top search providers for August 2009, viewed 01 May 2010 from http://searchenginewatch.com/3634991

position after Yahoo!. Over the past five years Google was the only search engine that demonstrated continuous growth in search engine market share as opposed to the other search engines (Sullivan 2004; Sullivan 2006; Searchenginewatch 2009). Table 1 illustrates each of the three major search engines with their respective search engine market share.

Search engines make use of artificial intelligence programs called website crawlers or spiders that 'crawl' the Internet and index websites. Indexing a website is when search engine crawlers create a duplicate of each webpage, saving the replica in a data repository (index) as search engines associate a webpage to a particular Uniform Resource Locator (URL). When a user does a search, the Search Engine Result Page (SERP) listings returned to the visitor are extracted from the search engine repository and not from the Internet (Weideman 2009:24). The link in each listing is thus a pointer to the appropriate website (Searchenginewatch 2007; Visser 2007:24-36).

Search engines make use of crawlers for indexing, with interpretation limitations; this indicates that the content used on a website is the one primary SEO element that provides fundamental information to search engines about a particular website. This fact is confirmed by each of the three major search engines in their respective 'guidelines for best practices':

\section{Google:}

- 'Create a useful, information-rich site, and write pages that clearly and accurately describe your content' (Google 2010c).

- 'One of the most important steps in improving your site's ranking in Google search results is to ensure that it contains plenty of rich information that includes relevant keywords, used appropriately, that indicate the subject matter of your content' (Google 2010b).

- 'If fancy features such as JavaScript, cookies, session IDs, frames, DHTML, or Flash keep you from seeing all of your site in a text browser, then search engine spiders may have trouble crawling your site' (Google 2010c).

- 'Frames can cause problems for search engines because they don't correspond to the conceptual model of the web. In this model, one page displays only one URL' (Google 2010a).

\section{MSN/Live/Bing:}

- 'In the visible webpage text, include words users might choose as search query terms to find the information on your website' (Live 2010).

- 'Don't put the text that you want indexed within images' (Live 2010).

3. Yahoo!:

- 'Original and unique content of genuine value' (Yahoo 2010).

Considering the content recommendations by Google, Yahoo! and MSN/Live/Bing, many authors have also discovered and emphasised that sufficient content is an essential SEO element (Visser 2007:118; Weideman and Chambers 2005; Kritzinger and Weideman 2008; Eisenberg et al. 2008:222; Weideman 2009:59-60). As noted earlier, sufficient text content will ensure both a yield of enough keywords for a visiting crawler and content of value for the human visitor.

\section{Trust and credibility}

Search engine optimisation contradiction: Some authors emphasise that the WU attributes of trust and credibility (privacy policy, about us, company overview, feedback, testimonials and contact form) should be prioritised on all websites. This WU attribute is in contradiction with SEO as the content utilised in the sub-attributes have no direct association with what visitors search for (product or visitors needs) as described above in search engine guidelines for best practices.

\section{Single page view, content and frames}

Search engine optimisation contradiction: Single page views and content limitations (as suggested by WU experts) prevent search engines from eliciting a better interpretation of any given websites' purpose. The more content a website has the more weight-carrying key phrases the website could potentially rank for. Search engines reward qualitative and quantitative websites (featuring solid, informative and useful content) with good rankings for specific search terms or phrases.

Frames can be described as separate rectangular blocks all present on a single webpage. Each frame contains its own content, which functions independently from any other frame on the same webpage. Frames thus prevent search engines from associating an entire webpage to a particular URL, implying that the content utilised on a frame based website is in fact invisible to search engines. As a result, frames are often listed as an undesirable website design element - their absence is claimed to improve website visibility (Weideman 2009:114).

\section{Keywords}

Search engine optimisation contradiction: Keyword variations, frequency and density are essential for SEO. This forms part of a technology named 'theme-ing', used to emphasise products or business elements (keywords) to search engines. WU authors believe that increasing the 
keyword frequency and density could reduce readability (Nielsen \& Loranger 2006:166).

\section{Images}

Search engine optimisation contradiction: Visitors often prefer graphic-based webpages as opposed to text-based webpages. Search engines are unable to read or interpret any text placed within an image. If text (especially keywords) is placed within images, that text is invisible to search engine crawlers. Text within images can therefore not assist search engines to be more successful at interpretation of any given websites' purpose. In summary, if any webpage content on any website cannot be indexed or interpreted correctly, then those webpages cannot possibly rank for targeted keywords.

\section{Methodology}

The following website usability attributes, which are in conflict with SEO elements, were examined in a pre-test posttest, quantitative methodological design:

- Trust and credibility: Essential for WU, but adds no value to SEO as the non related content could dilute emphasis for ranking purposes.

- Single page view and content: Essential for WU, but search engines rely on content to better interpret a website's content and keyword emphasis for ranking purposes.

- Keywords: Avoiding keyword overload is essential for WU. However, search engines depend on keyword density and inclusion for emphasis purposes in terms of ranking.

- Images: Essential for WU in terms of being aesthetically pleasing to visitors. Unfortunately, search engines are unable to make an accurate interpretation of images and can thus reduce content and keyword emphasis in terms of ranking.

The primary experiment includes the use of an existing website (created by a non-technical designer with minimal knowledge of WU and SEO), which was used as the control website (CW: www.copywriters.co.za). A new website was developed by implementing the above WU attributes and ignoring all contradictory SEO elements, termed the experimental website (EW: www.copywriters.co.za/ppc/). The $\mathrm{EW}$ was placed in a subdirectory of the $\mathrm{CW}(/ \mathrm{ppc} /)$, allowing the EW to function independently from the $\mathrm{CW}$. In order to ensure integrity of the experiment, a robots.txt file was placed in the root of the www.copywriters.co.za website, explicitly instructing the search engine crawlers not to index the EW (/ $\mathrm{ppc} /$ ). In addition, no links of any kind were created from the $\mathrm{CW}$ to the EW and vice versa. The EW is thus accessible only via the URL (i.e. via a direct link to the EW).

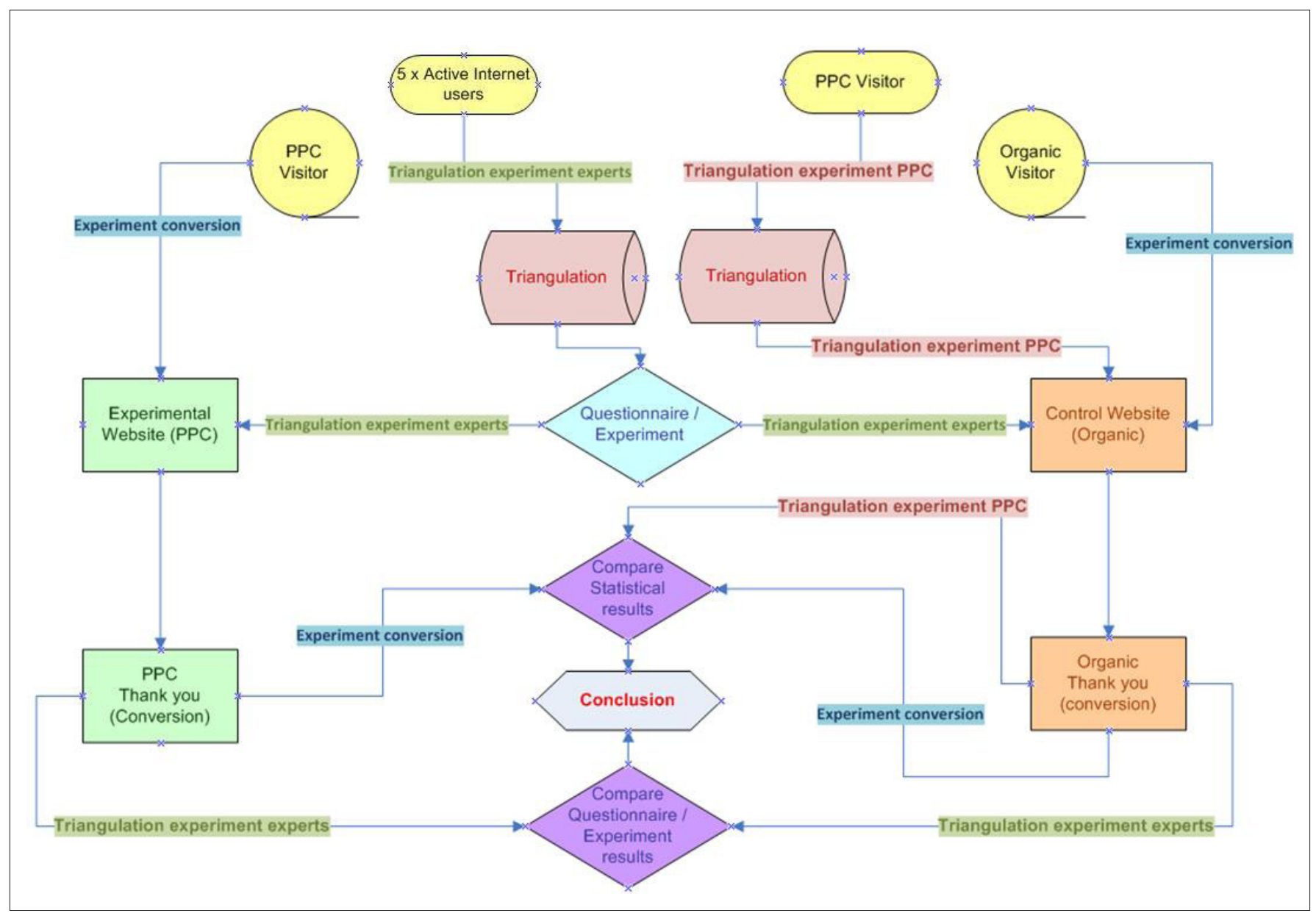

FIGURE 1: Research design diagram. 


\section{Control website}

Search engine traffic consists of two types: organic (unpaid search result listings) and Pay Per Click, also known as PPC (paid search result listings). The traffic sources for the $\mathrm{CW}$ are search engines (organic) traffic, as well as direct and referrer traffic. Direct traffic is when a visitor visits the CW directly (by typing in the URL directly into the browser or by means of bookmarks and/or favourites), without making use of a search engine. Referrer traffic is when a visitor visits the $\mathrm{CW}$ via a link from another website, also without making use of a search engine (Google 2009).

Organic results occupy the primary real estate (left and centre) of the SERPs. These organic search results are governed by search engine algorithms, which are kept secret to avoid abuse. The better a particular website satisfies the search engine algorithm according to a keyword search, the better that particular website will rank organically (Neethling 2008:3). Good organic search results do not guarantee financial success. However, theoretically the better a particular website ranks, the more traffic that website should receive due to the fact that on average $67 \%$ of search engine users do not look beyond the first SERP (Weideman 2009:32).

\section{Experimental website}

The traffic source for the EW is purely PPC. PPC results occupy the right side and in some instances the top of a typical SERP. The use of an organic search engine algorithm does not apply to PPC results at all. However, an algorithm does exist to determine the priority ranking of PPC results by means a basic formula:

PPC ranking $=$ quality score $\mathrm{x}$ bid price.

The bid price is determined by the user, whilst the PPC search engine algorithm uses a number of factors to determine the quality score.

Both the CW and the EW sell the exact same products. However, the way in which the two websites draw visitors differ, which indicates that the website traffic source alone cannot be utilised as a performance measuring tool. Thus performance measurements were made by considering the number of conversions obtained from the amount of website traffic obtained (conversion or traffic ratio) of each website over the same period of time, which were then compared (keeping the traffic source in mind). Additional factors, such as time spent on site, page views and Return On Investment (ROI) were also considered as measuring tools.

For triangulation purposes, an interview was conducted with five active Internet users as part of the experiment. A number of questions were created with the purpose of obtaining fundamental information as to the actual impact of each WU attribute. The interview results combined with the statistical results provided a clear indication as to whether WU attributes affect 'on page' conversion. Lastly, on completion of the first experiment, the experimental traffic source (PPC) was redirected to the $\mathrm{CW}$ for the same period of time. The objective was to test the PPC traffic source (as a 'trusted' traffic source), by exposing similar visitors to the $\mathrm{CW}$ as exposed to the EW for comparison purposes (Figure1).

The research design diagram (Figure 1) can be divided into four vertical parts (conceptually). Each vertical part represents a portion of the experiment:

- PPC visitors on the far left - primary experiment

- $5 \times$ Active Internet users just to the left of the centre line - triangulation

- PPC visitors just to the right of the centre line triangulation

- Organic Visitors on the far right - primary experiment.

\section{Results}

The CW has been active on the Internet since 2006, obtaining visitor traffic from a variety of sources. Website traffic statistics for the CW was obtained over the same period as the EW. The EW was launched in December 2009, obtaining visitor traffic from PPC only. The EW PPC campaign (targeting only Google) was created on the same day the EW was launched, with a budget of R5257.17 for the duration of 49 days. The PPC campaign towards the EW was terminated on the 31st of January 2010.

During the 49 days the $\mathrm{CW}$ and the EW combined received 8020 visitor traffic from all traffic sources ('All visitors'; see Figure 2 for the graphical presentation of these results). Of the 8020 visitors, 5544 were non search engine visitors ('NON SE T'; see Figure 2), indicating that 5544 visitors landing on the $\mathrm{CW}$ only from referrer websites and/or direct traffic. The remaining 2476 visitors was search engine traffic ('SE $\mathrm{T}^{\prime}$; see Figure 2), which included PPC traffic. This indicates that both the CW and the EW received a combined volume of search engine traffic of 2476 visitors. The 2476 search engine traffic visitors were then categorised into organic (true search engine traffic) and PPC (paid search engine traffic). The analysis indicated that the total organic search engine traffic was 782 visitors ('SE Organic T'; see Figure 2) and the total

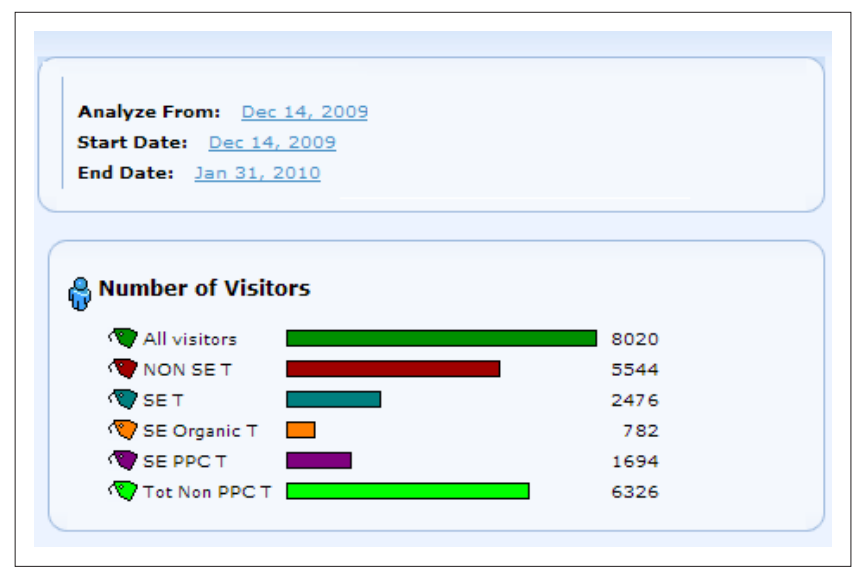

FIGURE 2: Snapshot breakdown and analysis of website traffic. 
PPC search engine traffic was 1694 visitors ('SE PPC T'; see Figure 2).

The analysis indicated that a grand total of 1694 visitors landed only on the EW over a period of 49 days ('SE PPC $\mathrm{T}^{\prime}$; see Figure 2). Subtracting 1694 PPC visitors from 8020 all visitors or adding 5544 non search engine traffic visitors to 782 organic search engine traffic visitors produces a grand total of 6326 visitors, which landed only on the $\mathrm{CW}$ only over a period of 49 days ('Tot Non PPC T'; see Figure 2).

\section{Control website (www.copywriters.co.za)}

The CW received 6326 visitors (from various sources) over a period of 49 days. These 6326 visitors viewed on average 1.5 webpages per visit. Each visitor spent on average 55 seconds on the website. Considering the number of visitors that landed on the $\mathrm{CW}$ and webpages viewed and time spent on the website over a period of 49 days; 21 unique visitors submitted the contact form successfully (converted into a lead). Of these 21 conversions, two visitors actually purchased the service to the total value of R2071.48.

\section{Experimental website (www.copywriters.co.za/ppc/)}

The EW received 1694 visitors (from PPC only) over a period of 49 days. The 1694 visitors viewed on average 1.1 webpages per visit. Each visitor spent on average 17 seconds on the website. Considering the number of visitors that landed on the EW and webpages viewed and time spent on the website over a period of 49 days; 59 unique visitors submitted the contact form successfully (converted into a lead). Of the 59 conversions, four visitors actually purchased the service to the total value of R5128.85 (Table 2).

\section{Statistical analysis}

A statistical analysis was done on the results of the primary experiment to determine whether or not there is a statistically significant difference in the measured variables between the CW and the EW. The test initially intended for this experiment was the Student's $T$-test. However, due to the population values not following a normal distribution, it was decided to use a non-parametric method to compare distributions. The statistical analysis was thus based on the Mann-Whitney $U$ test. The summary the statistics for each variable, which includes the $p$-value and identifies whether the $p$-value is significant or not (Table 3).

This analysis indicates that Visitors, Average Page Views per Visits and conversions are all significantly different when comparing the $\mathrm{CW}$ values to the EW values. Average time on site per Visitor was not considered as being significantly different. This was due to four extremely large values obtained on the EW, which resulted in an increased mean. The ROI was also not considered as being significantly different. The reason being that, out of 77 conversions, only six conversions actual resulted into sales. Comparing four sales for the EW to two sales from the CW is not statistically sound, due to the difference in sample size.

\section{Triangulation}

It was deemed prudent to use the opinions of active Internet users to confirm or reject the WU attributes analysed in the primary experiment. The secondary objective for the interview was to identify any additional WU attributes that may have been overlooked, which would encourage users to complete the online process as per the primary experiment. It was considered necessary because WU can best be interpreted by actual website users.

An interview was arranged with five randomly selected participants with a minimum of 10 years of Internet exposure and activity. The interviews were done face to face allowing the participant to browse through each website before and during the interview. The participants were also instructed to make an enquiry on each website prior to the interview. The interview questions were predominantly closed and set on the WU attributes identified and applied in the primary experiment. Three of the interview questions were open ended, providing each participant the opportunity to make any additional WU comments and/or recommendations in terms of enticing the visitor to convert on each (CW \& EW) website.

TABLE 2: Analysis of the control website (CW) traffic versus the experimental website (EW) traffic (primary experiment).

\begin{tabular}{lccccc}
\hline Combined number of visitors $\mathbf{8 0 2 0}$ & Visits & \multicolumn{2}{c}{ Average } & \multicolumn{2}{c}{ Conversions } \\
\cline { 3 - 5 } & & Page views per visitor & Time On Site (in seconds) & \\
\hline Control website & 6326 & 1.5 & 55 & 21 \\
Experimental website & 1694 & 1.1 & 17 & R2071.48 & 56 \\
\hline
\end{tabular}

ROI, Return On Investement.

TABLE 3: Summarised statistics for each variable.

\begin{tabular}{llll}
\hline Variables & Mann-Whitney $\boldsymbol{U}$ Test & $\boldsymbol{p}$-Value & Conclusion \\
\hline Visitors & 2208 & $<0.001$ & Significant Difference \\
Average Page Views per Visit & 1664 & $<0.001$ & Significant Difference \\
Average Time on site per Visit & 1343 & $>0.05$ & No Significant Difference \\
Conversion & 780 & $<0.006$ & Significant Difference \\
Return on Investement (ROI) & 1053 & $>0.05$ & No Significant Difference \\
\hline
\end{tabular}




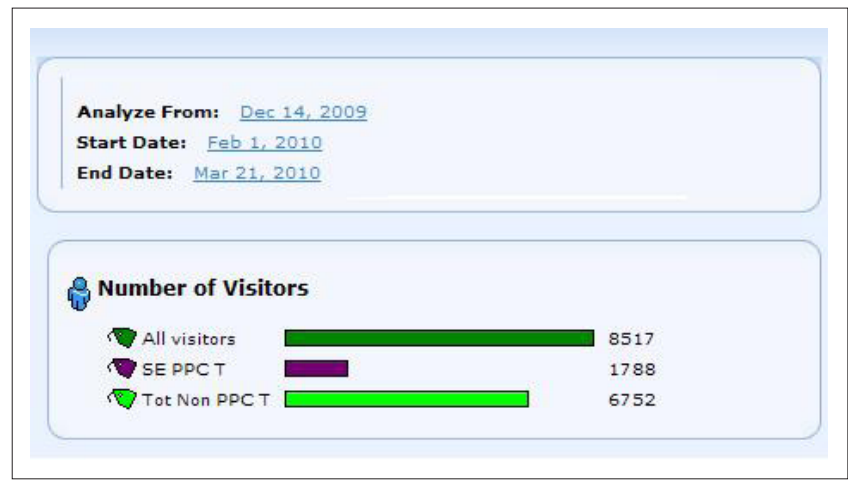

FIGURE 3: Triangulations - Snapshot breakdown of traffic sources.

The accumulated results obtained from the interviews leaned towards the importance of security, minimising content and making the contact form as easy as possible to complete. The only additional attribute that was mentioned was the design factor. Although identified by an interviewee, the design factor was not considered due to the subjective nature of such an attribute.

As part of triangulation, PPC traffic was redirected from the $\mathrm{EW}$ to the $\mathrm{CW}$ for 49 days after the primary experiment had ended. Therefore EW was made dormant, allowing the $\mathrm{CW}$ to receive all forms of traffic. The objective of the triangulation experiment was to test PPC as a traffic source in order to determine the quality of PPC traffic visitors in terms of conversions.

During the 49 days, the CW received 8517 visitors from all traffic sources, including PPC traffic ('All visitors'; see Figure 3). Of the 8517 visitors, 6752 visitors were non PPC visitors ('Tot Non PPC T'; see Figure 3). The remaining 1788 visitors were PPC visitors ('SE PPC T'; see Figure 3).

Table 4 provides the comparison between the triangulation experiment and the primary experiment. The triangulation experiment obtained PPC traffic along with all other forms of traffic (search engine, direct and refer traffic). The EW (from the primary experiment) obtained PPC traffic only.

Table 4 indicates that during the triangulation experiment, the CW drew 8517 visitors (all forms of traffic), of which only 29 visitors converted. The EW (in the primary experiment) conversely received 1694 visitors from PPC only, whereby 56 visitors converted.

The fact remains that the triangulation experiment obtained five times more traffic (including PPC traffic) than the EW (primary experiment). However, the EW obtained approximately $50 \%$ more conversions as opposed to the number of conversion obtained during the triangulation experiment.

Although it is generally perceived that PPC is a 'trusted' traffic source, the PPC traffic in this instance did not radically increase conversions. When considering Table 4 in terms of conversions obtained, it is clear that the traffic source as such is thus not a variable to consider that may have an impact on conversions in this instance. In addition, it is generally accepted that the more traffic a website receives, the more visitors should convert. This indicates that WU is the real impact factor in terms of conversion during the primary experiment.

\section{Conclusion}

The primary objective of this research project was to determine the WU attributes which are in contradiction with SEO elements. Although some experts in both fields do not acknowledge that any contradiction exists, the literature review clearly identifies those contradictions. WU experts specify that certain WU attributes will affect 'on page' conversions, which are in contradiction to the SEO elements, whereby some of these SEO elements are specified by the major search engines in their best practice guidelines.

The secondary objective of this research project was to determine whether or not WU attributes identified do in fact have an effect on conversions. The primary experiment provides evidence that WU attributes do have an effect on conversion. Depending on the purpose of any particular website, whether it is to entice a visitor to buy, sign up for a newsletter, create an account, request a quote or anything that requires the visitor to interact with any website form, suggests that WU is not a luxury, but a prerequisite for that particular type of websites' success.

The results from the primary experiment (Table 2) indicate that the CW obtained three and a half times more traffic than the EW. However, the EW obtained almost three times the amount of conversions obtained by the CW. Although the ROI was not considered as being significantly different in terms of the $p$-value, it still provides some indication as to the value of the applied WU attributes.

As part of the project, an interview was conducted for triangulation purposes. The objective of the interview was to get active Internet users to confirm or reject the WU attributes analysed in the primary experiment. The secondary objective for the interview was to identify any additional WU attributes that may have been overlooked which would encourage users to complete the online process as per the

TABLE 4: Summary and comparison of the triangulation experiment and the experimental website (primary experiment)

\begin{tabular}{lcccc}
\hline Website & Visits & \multicolumn{2}{c}{ Average } & \multicolumn{2}{c}{ Conversions } \\
\cline { 2 - 4 } & & Page views per visitor & Time On Site (in seconds) & \\
\hline Control Triangulation & 8517 & 1.4 & 21 & 29 \\
Experimental & 1694 & 1.1 & 17 & R1497.00 \\
\hline
\end{tabular}

ROI, Return on investment. 
primary experiment. The results obtained merely confirmed the importance of the WU attributes already identified.

Lastly, a triangulation experiment was conducted in order to test PPC as a traffic source in terms of conversion. PPC visitors can be considered to be more serious about making a purchase. The triangulation experiment provided evidence that the traffic source is not really a variable to consider in this instance.

The limitations of this research project include that it was decided to use a non-parametric method to compare distributions. It was done due to the population values not following a normal distribution (which made direct comparison difficult). Furthermore, the research was conducted over a relatively short period of time (49 days). Finally the fact that two different sized samples were used made statistical comparison harder.

The next logical step would be to test the SEO elements and ignore all contradicting WU attributes. A second experimental website (EW2) could be created, whereby the rankings of the $\mathrm{CW}$ can be compared to the rankings of the EW2. Conversion and/or traffic ratio of each website (CW \& EW2) can also be measured over the same period of time (49 days), which can then be compared not only to one another, but also the results obtained in the EW. The results obtained will further indicate the impact of the SEO and WU contradictions. This might also be a good opportunity to investigate the possible 'theme-ing' technology and its effectiveness.

\section{References}

Barnard, L. \& Wesson, J.L. 2003, 'Usability issues for E-commerce in South Africa: An empirical investigation', Proceedings of the Annual Conference of the South African Institute of Computer Scientists and Information Technologists (SAICSIT), Pretoria, 2003, September 17-19, pp. 258-267.

Bevan, N., 2005, 'Guidelines and Standards for Web Usability', Proceedings of the 11th International Conference on Human-Computer Interaction, Las Vegas, 2005, July 22-27, pp. 1-10.

Bruno, V. \& Al-Qaimari, G. 2004, 'Usability Attributes: An Initial Step Toward Effective User-Centred Development', Proceedings of the Annual Conference of the Australian Computer-Human Interaction Special Interest Group (CHISIG) of the Australian Computer-Human Interaction
Wollongong, 2004, November 22-24, pp. 1-4.

Eisenberg, B., Quarto-vonTivadar, J., Davis, L.T. \& Crosby, B., 2008, Always be testing: The complete guide to Google website optimizer, Sybex, Indianapolis.

George, C.A., 2005, 'Usability testing and design of a library website: An interactive approach', OCLC System \& Services 21(3), 167-180. doi:10.1108/10650750510612371, PMCid:2431148

Google, 2009, Back to Basics: Direct, referral or organic - definitions straight from the source, viewed 02 May 2010, from http://analytics.blogspot.com/2009/08/backto-basics-direct-referral-or.htm
Google, 2010a, Frames, viewed 29 April 2010, from http://www.google.com/support/ webmasters/bin/answer.py?hl=en\&answer $=34445$

Google, 2010b, Little or no original content, viewed 01 May 2010, from https://www. google.com/support/webmasters/bin/answer.py?hl=en\&answer=66361

Google, 2010c, Webmaster guidelines, viewed 27 April 2010, from http://www. google.com/support/webmasters/bin/answer.py?hl=en\&answer=35769

James, J.P., 2002, 'Usability and usefulness of ergonomics web sites: a preliminary investigation', South African Journal of Information Management 4(1), viewed 02 May 2010, from http://www.sajim.co.za

Johnson, J., 2007, GUI Bloopers 2.0, Second Edition: Common User Interface Design Dont's and Dos. Morgan Kaufmann, San Francisco.

Johnson, J., 2008, Web Usability in 2008: Mediocre, viewed 01 May 2010, from http:// www.uiwizards.com/WebUsability2008.pdf

Kritzinger, W.T. \& Weideman, M., 2008, 'Finding the synergy: search engine optimization vs. website usability', Proceedings of the 10th Annual Conference on World Wide Web Applications, Cape town, 2008, September 3-5, viewed 04 May 2010, from http://www.zaw3.co.za

Live, 2010, Guidelines for successful indexing, viewed 01 May 2010, from http://help. live.com/help.aspx?mkt=en-US\&project=wl_webmasters

Murphy, H.C. \& Kielgast, C.D., 2008, 'Do small and medium-sized hotels exploit search engine marketing?', International Journal of Contemporary Hospitality Management 20(1), 90-97. doi:10.1108/09596110810848604

Neethling, R., 2008, 'Search engine optimisation or paid placement system-use preference' unpublished MTech thesis, Dept. of Information Technology, Cape Peninsula University of Technology, Cape Town.

Ngindana, M.W. \& Weideman, M., 2004, 'Visibility to search engines: A comparison between text-based and graphic-based hyperlinks on e-Commerce websites', Proceedings of the 6th Annual Conference on World Wide Web Applications, Johannesburg, 2004, September 1-3, Johannesburg, viewed 01 May 2010, from http://www.zaw3.co.za

Nielsen, J. \& Tahir, M., 2001, Homepage usability: 50 websites deconstructed, New Riders Press, United States of America.

Nielsen, J. \& Loranger, H., 2006, Prioritizing web usability, New Riders Press, Berkeley.

Nielsen, J., 2003, Usability 101: Introduction to usability, viewed 02 May 2010, from http://www.useit.com/alertbox/20030825.html

Nielsen, J., 2005, Web usability: The top ten design mistakes, viewed 04 May 2010, from http://www.useit.com/alertbox/weblogs.html

Nielsen, J., 2007, Top ten mistakes in web design, viewed 01 May 2010, from http:// www.useit.com/alertbox/9605.html

Searchenginewatch, 2007, How search engines work, viewed 02 May 2010, http:// searchenginewatch.com/2168031

Searchenginewatch, 2009, Top search providers for August 2009, viewed 01 May 2010, from http://searchenginewatch.com/3634991

Sullivan, D, 2004, Google tops, but Yahoo switch success so far, viewed 04 May 2010, from http://searchenginewatch.com/3334881

Sullivan, D., 2006, Nielsen NetRatings Search Engine Ratings, viewed 01 May 2010, from http://searchenginewatch.com/2156451

Visser, E.B., 2007, 'Search engine optimisation elements' effect on website visibility: The Western Cape real estate SMME sector', unpublished MTech thesis, Dept. of Information Technology, Cape Peninsula University of Technology, Cape Town.

Weideman, M. \& Chambers, R., 2005, 'Application of best practice towards improving Web site visibility to search engines: A pilot study', South African Journal of Information Management, 7(4), viewed 30 April 2010, from http://www.sajim. co.za

Weideman, M., 2009, Website Visibility: The Theory and Practice of Improving Rankings, Chandos Publishers, Oxford. Yahoo, 2010, Yahoo! Search content quality guidelines, viewed 01 May 2010, from http://help.yahoo.com/l/us/yahoo/ search/basics/basics-18.html

Zuze, H. \& Weideman, M., 2010, 'Keyword density in website body text - search engine spamdexing? Poster presentation', Proceedings of the 12th World Wide Web conference (ZAW3-10), Durban, 2010, September 21-23. 